\title{
A MODERN ACCIDENT SERVICE
}

\author{
G. P. Arden, M.B., F.R.C.S., W. Herschell, M.B., F.R.C.S., and R. H. Maudsley, M.B., F.R.C.S. \\ Accident Service, Windsor Group of Hospitals
}

The need for an organized and efficient accident service to cover large towns or groups of smaller ones is increasingly apparent. The growing number of cars on the road, the complexity of modern factories, the mechanization of farming and of the home brings the number of accidents to a higher total each year.

Accidents are responsible for $80 \%$ of all deaths under the age of 18 and, in addition, many young people are being permanently disabled. In 1957 in England and Wales there were 21,561 deaths from accidents, poisonings and violence (12,858 males and 8,703 females). A far greater number have been injured from the same causes.

Prior to the last war a few hospitals had developed highly efficient accident departments mainly in the big towns and areas of heavy industry. However, an accident service covering scattered areas of light industry, farming and residential districts has not generally been available. With the coming of the Health Service it has been much easier to improve these services and integrate whole areas into one accident service.

Two forms of accident service have emerged. Firstly, the specialized accident hospital staffed by accident surgeons who treat every form of injury, such as the Birmingham Accident Hospital organized by Gissane. The other type is the accident service in a general hospital, such as the Radcliffe Infirmary, which is in the charge of orthopaedic surgeons who have the help of associated specialists, i.e. plastic surgeon, neurosurgeon, thoracic surgeon, genito-urinary surgeon, etc. The majority of areas have adopted the latter form, as it is felt that the specialist surgeon is the best person to cope with specialized injuries. For instance, the genito-urinary surgeon can deal best with a ruptured bladder. An accident surgeon would only have occasional opportunities to deal with this injury, whereas the genito-urinary surgeon is commonly opening or dealing with the bladder. The same applies to other specialties, such as neuro-surgery or chest surgery.

The orthopaedic surgeon is responsible for resuscitation and treatment of all skeletal injuries and he calls in the other specialties as required.
It is convenient to divide all accidents into two types:

(a) Major injuries are those requiring admission to hospital.

(b) Minor injuries are those requiring casualty treatment only.

We believe that all major injuries should be taken at once from the scene of the accident to the major accident unit for the area, by-passing all other hospitals so as to ensure the most efficient treatment. The only practical way to work such a scheme would be with the co-operation of the police and ambulance services.

It would be, of course, difficult for ambulance workers and police at the site of an accident to decide whether a casualty is a major injury. It should be assumed that every injury requiring an ambulance should be regarded as a major injury until decided otherwise by a doctor. A certain number of minor injuries will inevitably be taken on an unnecessary long journey to the accident unit.

While it is important that major injuries should be treated as described below to save life and reduce disability and suffering, it is equally important that minor injuries should be treated at the local hospital from the economic point of view. Far too much time is often wasted at present by patients attending casualty departments, involving unnecessary loss of time from work.

The major accident unit for the area must be in a general hospital and should consist of an accident reception unit and accident wards with 70 to 100 beds.

This unit should have the following facilities:

(I) It should be centrally placed geographically, but nearest the densest population and scene of most major accidents (road and industry).

(2) A fully-equipped accident department open day and night seven days a week.

(3) The casualty department must be staffed by an experienced senior accident officer and assistants, with readily available consultant cover.

(4) A 24 hours per day and seven days per week anaesthetic service. 
(5) A 24 hours per day and seven days per week emergency X-ray and pathological service.

(6) All associated specialties readily available, i.e.:

(a) Facio-maxillary and plastic surgeon (subcentre).

(b) Neuro-surgeon (sub-centre).

(c) Abdominal and urological surgeon.

(d) Thoracic surgeon.

(e) Eye surgeon.

(f) E.N.T. surgeon.

(g) Physician.

(h) Physical medicine specialist.

(7) Accident wards to be staffed by a sister (orthopaedically trained) and with special experience in accident work. This ward must always keep beds available for fresh cases.

(8) A blood bank sub-centre with mobile transfusion unit.

(9) A mobile major accident unit able to go to areas of a major disaster.

(I0) Its own operating theatre with specialized $\mathrm{X}$-ray equipment so that operating sessions are readily available throughout the week.

(II) Frequent fracture clinics and hand clinic each week.

(12) The services of orthopaedically trained after-care sisters.

Certain cases might need to be transferred to regional centres, i.e. neuro-surgical, thoracic, facio-maxillary or to units for burns and spinal injuries.

The minor accident unit is the nearest hospital to the patient's place of work or home.

The minor accident department must be an efficient unit whose function is to treat all accidents as before, except major injuries $(98 \%$ of their present work).

These units should be staffed and equipped to:

(I) Treat many minor injuries efficiently and quickly.

(2) Enable patients to be away from work or home duties for the minimum period.

(3) Provide an accident X-ray, pathological and physiotherapy service during the working hours for the working week.

(4) Have consultant-staffed fracture and hand clinics weekly.

(5) Be able to cope with a major accident in an emergency.

(6) Act as an integral part of the accident service of the area with opportunities for the medical and nursing staff to attend the major unit for lectures and conferences.

From this plan it will be seen that two types of accident departments are needed:

(I) A large department at the major accident unit fully equipped to treat major injuries of all types in large numbers.

(2) (a) A smaller department at the other hospitals designed for a rapid turnover of minor injuries and ye $t$ able on occasions to cope with a major injury, or

(b) An industrial health centre of the Slough or Harlow type on industrial sites according to their size.

It is realized that under this plan probably only $90 \%$ of the major injuries would go to the major unit. About 10\% might still go to the local hospital for a variety of reasons:

(a) Accident on the doorstep.

(b) Patient moribund.

(c) Demands by relatives and friends.

The accident service would provide on a weekly rota an orthopaedic surgeon and an after-care sister on emergency call to the whole area and available to all the hospitals.

Finally, a regional rehabilitation centre should be available with facilities for resettlement and retraining. This could serve group accident services. All major injuries should be sent there as soon as they are fit to leave hospital and later attend the clinics nearest their homes or places of work. If disability is permanent, then the rehabilitation unit, through industry or a Government training centre, could help the patient to start another career after suitable training.

\section{The Windsor Group Accident Service}

This serves a population of 260,000 , covering an area 20 miles by 16 miles, with the Thames passing through the middle. The main hazards are road accidents and industry.

There are about 300 factories of all sizes in Slough concerned with light industry and a smaller but increasing number of factories in Maidenhead and the new town of Bracknell.

The population of the area is increasing by about 10,000 a year because of the new town at Bracknell and the L.C.C. settlements in Slough.

Considerable integration and reorganization of accident work in our group has been possible since the coming of the Health Service as follows:

(I) All accidents in the group are treated by one accident service.

(2) One hospital in the group has a 24-hour seven days per week pathological and X-ray service.

(3) A 24-hour seven days per week anaesthetic service is available at all hospitals.

(4) A 29-bedded accident unit in a general hospital is available for the treatment of the more serious injuries.

(5) All associated specialties are readily avail- 


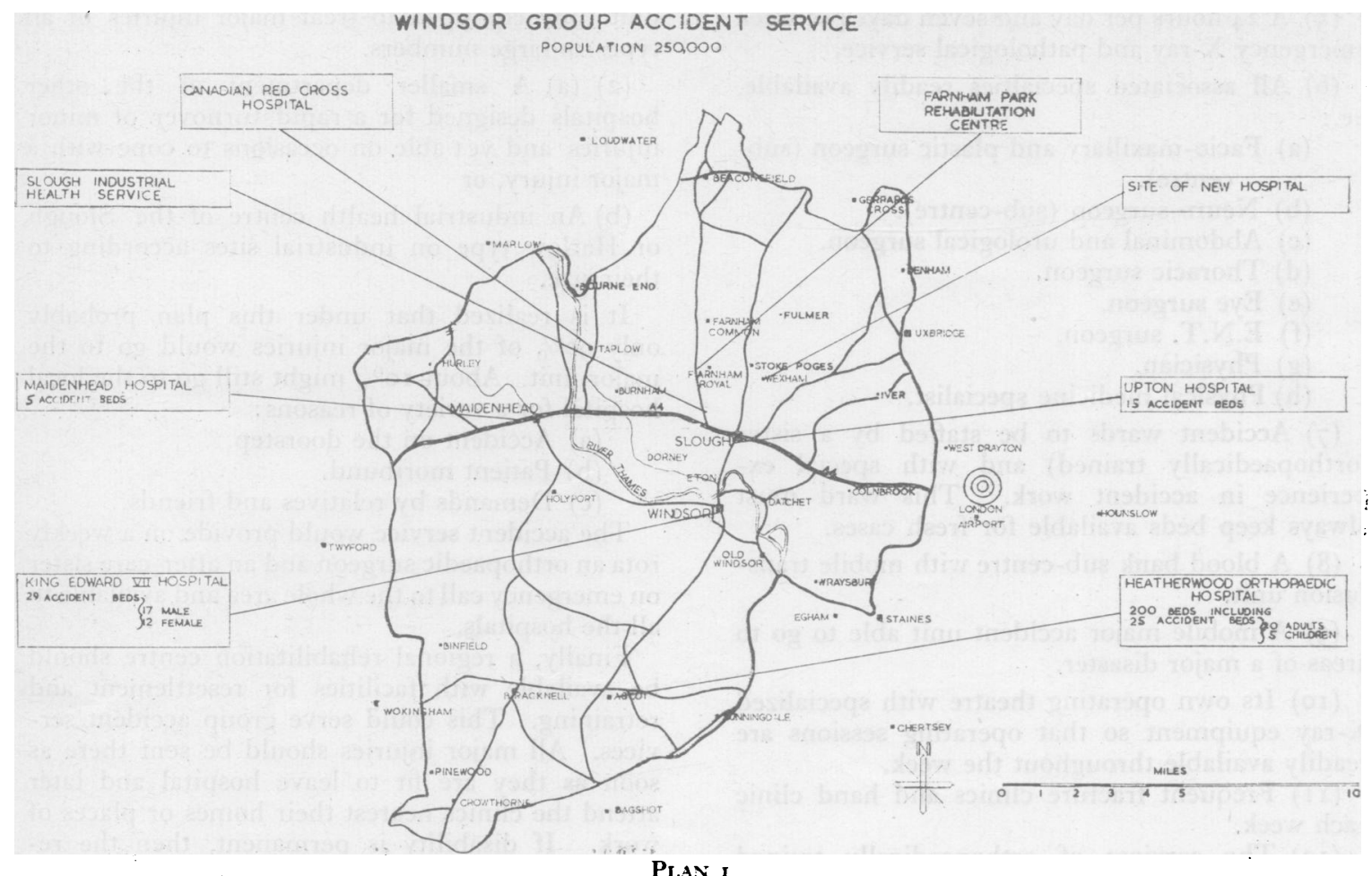

able in the group, in particular the plastic and facio-maxillary surgeon and neuro-surgeon.

(6) A mobile blood transfusion unit and mobile major accident unit are available.

\section{Table I.-Accident Cases in One Year}

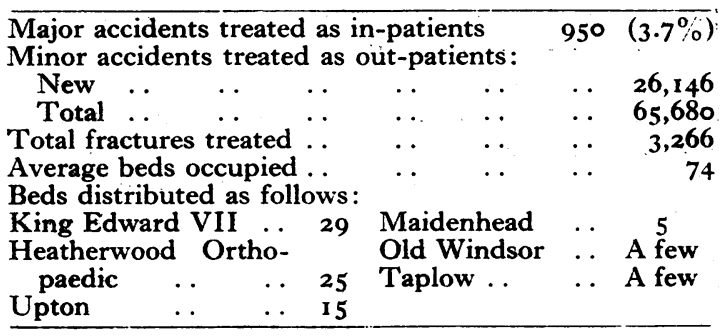

This accident service still suffers from the following disadvantages:

(I) Experienced casualty officers are difficult to obtain and too often at weekends at the small hospitals only unregistered house officers are available for the immediate treatment of accident cases.

(2) No casualty departments in the group are open after midnight.

(3) With one exception, lack of a 24-hour seven days per week pathological service causes delays in blood transfusions. A blood transfusion should be running within 15 minutes of a severely-shocked patient arriving.

(4) In some hospitals emergency X-ray services: are unreliable and delays result in diagnosis and treatment.

(5) There may be no beds available. The patient has to be transferred, resulting in delays and unnecessary movement. An injured patient should be tucked up in a warm bed within 30 minutes of arriving at hospital unless' more urgent treatment is required.

(6) Some patients have to be admitted to general surgical wards whose staff are inexperienced in the treatment of accident cases and equipment is inadequate.

(7) It is often difficult to find a free operating session for accident cases at short notice and delays occur in treatment.

(8) With accident cases in so many different hospitals it is not possible to equip each hospital fully. This may result in transferring patients at times.

We are fortunate in having a new 300 -bedded hospital being built next year at Slough, where we hope to have a 7o-bedded accident unit in a general hospital with a plastic and neuro-surgical subcentre. It is our intention to close all accident beds in the other hospitals and arrange for all 


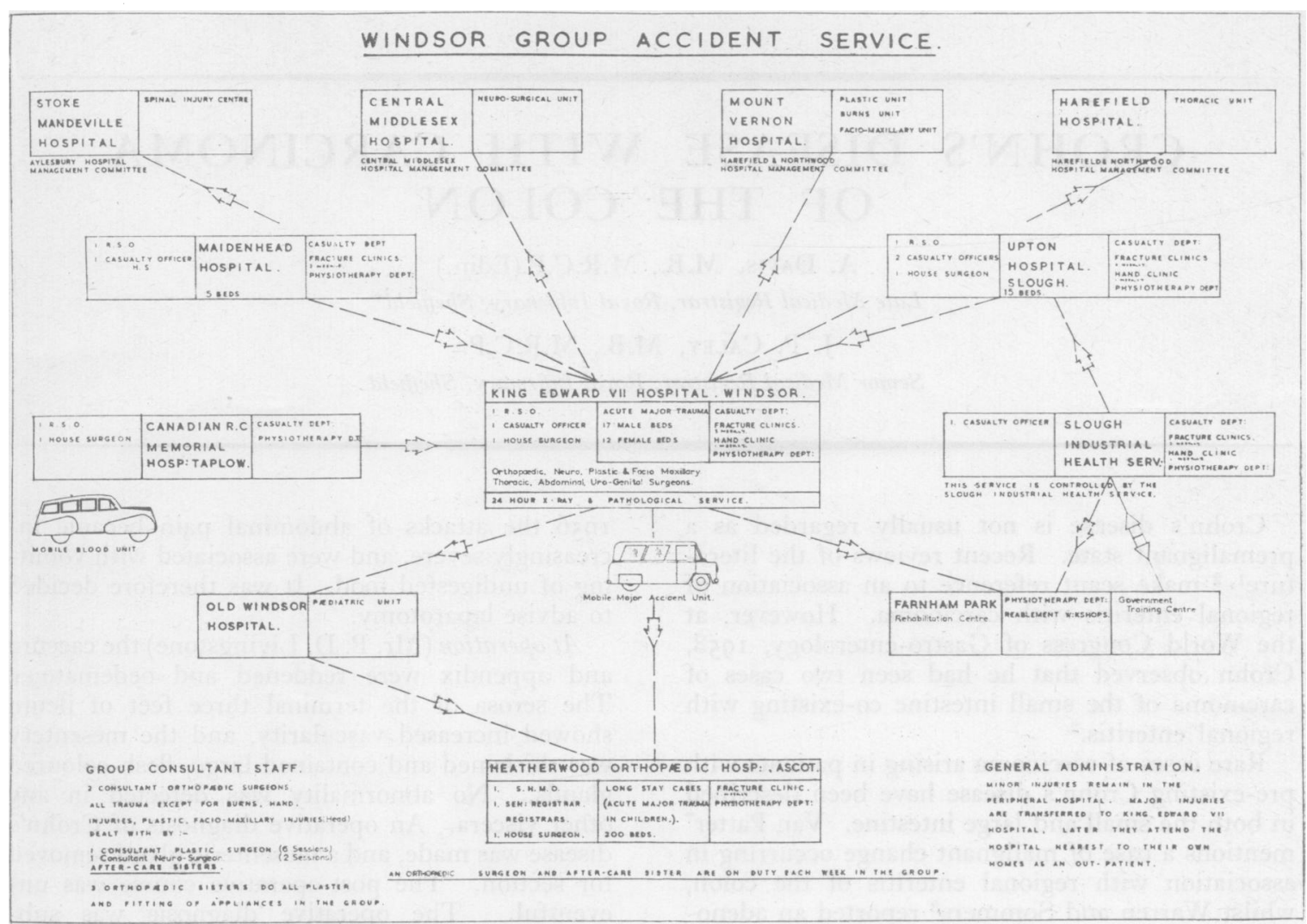

PlaN 2

accident cases in our area requiring an ambulance to be taken direct to the accident reception centre at this new hospital.

On the other hand, we intend to maintain and improve the casualty departments of the other hospitals so as to treat the many minor injurics promptly and efficiently with an emphasis on the economic importance of their injuries.

Analysis of cases attending our casualty departments at present show:

$$
\begin{array}{llr}
\text { Trauma. . } & \ldots & 92.8 \% \\
\text { Non trauma } & \ldots & \mathbf{7 . 2} \%
\end{array}
$$

These cases can be further subdivided as follows:

(I) Orthopaedic $\quad \ldots \quad \ldots \quad \ldots \quad 56.3 \%$

(2) Hand injuries and plastic cases
(burns, facial injuries) ..

(3) Eye injuries $\quad \ldots \quad \ldots \quad \ldots \quad \ldots \quad 10.0 \%$

$\begin{array}{lllll}\text { (4) Medical cases } \quad \ldots & \ldots & \ldots & 4.0 \%\end{array}$

$\begin{array}{llllll}\text { (5) Surgical } & \ldots & \ldots & \ldots & \ldots & 2.8 \%\end{array}$

(6) E.N.T. injuries $\quad \ldots \quad$. . $\quad \ldots \quad 2.5 \%$

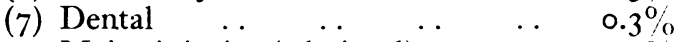
Major injuries (admitted). . $\quad . \quad 3.7 \%$ Minor injuries (not admitted) .. $\quad 96.3 \%$

Analysis of the total work done in the casualty departments at present shows that the treatment of
$96.5 \%$ of all new casualties, or $98.5 \%$ of total casualty attendances, is concerned with minor injuries. Again analysis of work in the minor operation theatre shows that $97.2 \%$ of all operations were for minor injuries.

Thus it will be seen that removing the major accidents from the other hospital casualty departments will reduce the work very little, but the interest of the major case would be lost. We hope, however, by regular talks and conferences to be held at the major unit for all medical and nursing staff in the Group Accident Service, to compensate for this.

We anticipate some opposition from doctors not familiar with the present-day problems of accident work and considerable opposition from lay members of H.M.C. and house committees who favour the old idea that an injured patient should be taken to the nearest hospital oblivious of what facilities exist there.

Finally, we feel the time has come to rename the casualty departments of hospitals 'accident departments,' where only accidents are treated.

\section{REFERENCES}

I. LOWDEN, 'T. G. (1955), 'The Casualty Department', published by Livingstone, Edinburgh and London.

2. Registrar General's Report, 1957, for Fngland and Wales. 